\title{
Electromagnetic survey around the seafloor massive sulfide using autonomous underwater vehicle
}

\author{
Tada-nori Goto ${ }^{1}$., Takafumi Kasaya ${ }^{2}$, Naoto Imamura ${ }^{1}$, \\ Hitoshi Mikada $^{1}$, Junichi Takekawa ${ }^{1}$ and Keizo Sayanagi ${ }^{3}$ \\ ${ }^{1}$ Dept. of Civil and Earth Res. Eng., Kyoto University \\ ${ }^{2}$ Japan Agency for Marine-Earth Science and Technology \\ ${ }^{3}$ Institute of Oceanic Research and Development, Tokai University
}

\begin{abstract}
The recent growth of world-wide requirement of metals demands advanced explorations for finding metal mine and deposits. The feasibility studies demonstrated that the electromagnetic responses are very sensitive to the conductive layer simulating the submarine massive sulfide (SMS) deposits, which is buried at the depth of several tens meters. On the basis of the results, we developed instruments for the marine controlled-source electromagnetic (CSEM) survey with autonomous underwater vehicle (AUV), on which a transmitter was attached. For the real field test, R/V Yokosuka and AUV Urashima were used. The target region is a real deep-sea mine in a caldera structure called Bayonnaise, located in the Izu-Bonin island arc, south of Japan. We succeeded in the test experiment along four survey lines with current shooting from AUV. Six ocean-bottom receivers (OBEM) simultaneously recorded those signals. The maximum source-receiver distance, in which we can detect the artificial current signals, exceeds to about $500 \mathrm{~m}$. Therefore, the inferred maximum sounding depth will be $150 \mathrm{~m}$ or more below the seafloor. For evaluating the anomalous attenuation or amplification of received electric field at OBEMs, the three-dimensional forward modeling including the real bathymetry and a simple subsurface structure having an uniform resistivity (1 Ohm-m) was employed. Comparison between the observed and synthesized received field gives us a three-dimensional pseudo-section of anomalous received field, which can visualize heterogeneity of sub seafloor structure qualitatively. On the basis of the preliminary result of our AUV-CSEM survey around the SMS, high conductive features are observed not only in the SMS exposed area, but also the surrounding area of SMS. It would reflect both the mineral deposits in and around the SMS and highly conductive pore water below the surface due to warm temperature by hydrothermal activities below the SMS. We conclude that our new technology imaging the near sub-seafloor structures will be useful for discussion about the geological background of SMS, and also be a powerful tool for the SMS detection and developments
\end{abstract}

\section{Introduction}

The recent growth of world-wide requirement of metals demands advanced explorations for finding metal mine and deposits. Especially, the submarine massive sulfides (SMS) have attracted mining companies because of its compactness with high grades. However, few exploration techniques were developed to evaluate the thickness of SMS and to find the buried SMS. For example, pioneer surveys around SMS were done in 1990's (e.g., Von Herzen et al., 1996; Cairns et al., 1996), but a number of observation points were limited and detailed structures are still unknown. Recently, Kowalczyk (2008) tried the resistivity mapping around a SMS using their own electromagnetic sounding system, however, only the observed responses are published and no information about seafloor resistivity distributions are reported.

Marine controlled-source electromagnetic
(CSEM) survey can give us information of sub-seafloor structures, and is intensively applied to exploration of hydrocarbons (oil / gas) in the recent years (e.g., Constable and Srnka, 2007). However, one of the great problems is the rough seafloor feature near the hydrothermal area, which restricts the ways for marine CSEM survey. The rough topography does not allow the towing just on the seafloor. The high altitude of towed cable gives us a chance of towing but the obtained data mainly reflect the seawater layer below the cable, so that the resolution to the sub-seafloor structure is decreased.

Here, we propose a new CSEM technique with autonomous underwater vehicles (AUVs) as shown in Fig.1. One AUV, with a transmitter, can move near the rough seafloor, and gives us a continuous CSEM survey along a profile near the rough seafloor. In our concept, the AUV-based CSEM survey system consists of two instruments; a 
transmitter and receivers attached to AUV and seafloor receivers. If the cruising altitude of AUV can be kept with a lower level $(<20 \mathrm{~m})$, the former can solely measure the seafloor resistivity with sounding depth of several meters, which is used for the resistivity mapping. However, a high cruising altitude $(>20 \mathrm{~m})$ will give us little information about the seafloor resistivity. The later seafloor receivers (ocean-bottom electromagnetometers= OBEMs, or ocean bottom electrometers= OBEs) give us a larger source-receiver separation, and allow us to obtain the deeper images below the seafloor.

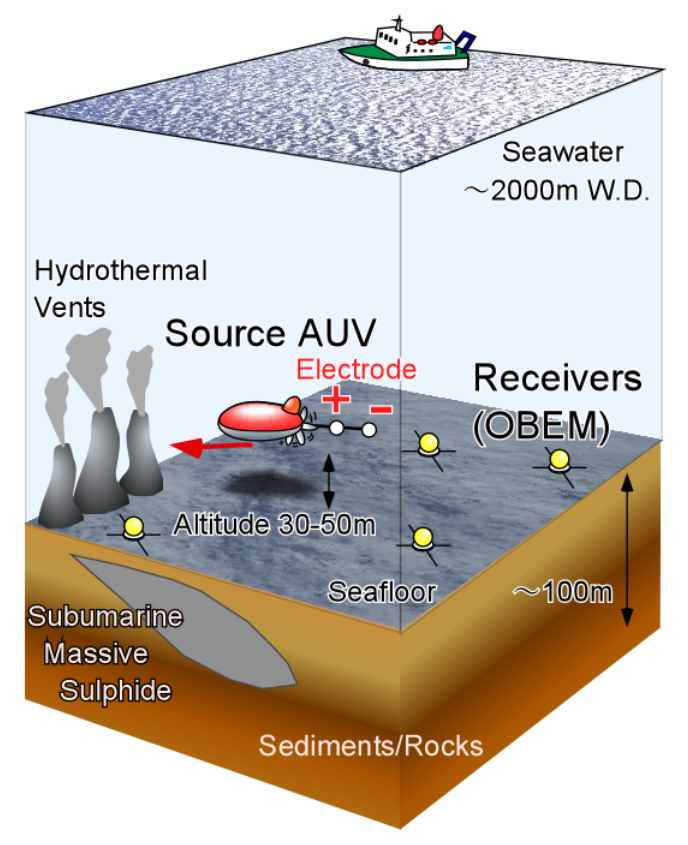

Fig. 1 AUV-CSEM survey on a hydrothermal area.

As discussed in Goto et al. (2009), if the SMS has higher conductivity $(5 \mathrm{~S} / \mathrm{m})$ than the surrounding rocks $(0.45 \mathrm{~S} / \mathrm{m})$, we found that the electromagnetic responses of AUV-CSEM survey are very sensitive to the buried conductive materials which simulate the SMS deposits. For example, the CSEM method with short source dipole length of $5 \mathrm{~m}$ makes anomalous attenuation of magnetic field $(>30 \%)$ with a source-receiver separation larger than $50 \mathrm{~m}$. Also, the received electric field with short dipole length of $5 \mathrm{~m}$ shows us anomalous attenuation of electric field $(<10 \%)$ with large source-receiver distance $(>100 \mathrm{~m})$. Therefore, we got some anomalies with CSEM survey even if we choose the short source dipole.

\section{Instruments and experiment}

We developed AUV-based controlled-source electromagnetic (CSEM) survey system which can be applied to exploration of seafloor massive sulfide (Fig.2). Our system can be attached to AUV, and allows us to image sub-seafloor resistivity structure with depth of several tens to hundreds meters. We deployed six OBEM/OBEs for receivers. The OBEM (Fig.2) was a self pop-up type, developed in 2005 . The acoustic communication allows the positioning of OBEMs on the seafloor and also to release the weight for lifting off toward the sea surface. The sampling rate is $8 \mathrm{~Hz}$. The resolutions of magnetic and electric field are $0.01 \mathrm{nT}$ and $0.01 \mathrm{microV} / \mathrm{m}$, respectively. The $\mathrm{Ag}-\mathrm{AgCl}$ electrodes are attached at the tip of arm of OBEM, with length of $2 \mathrm{~m}$ each.

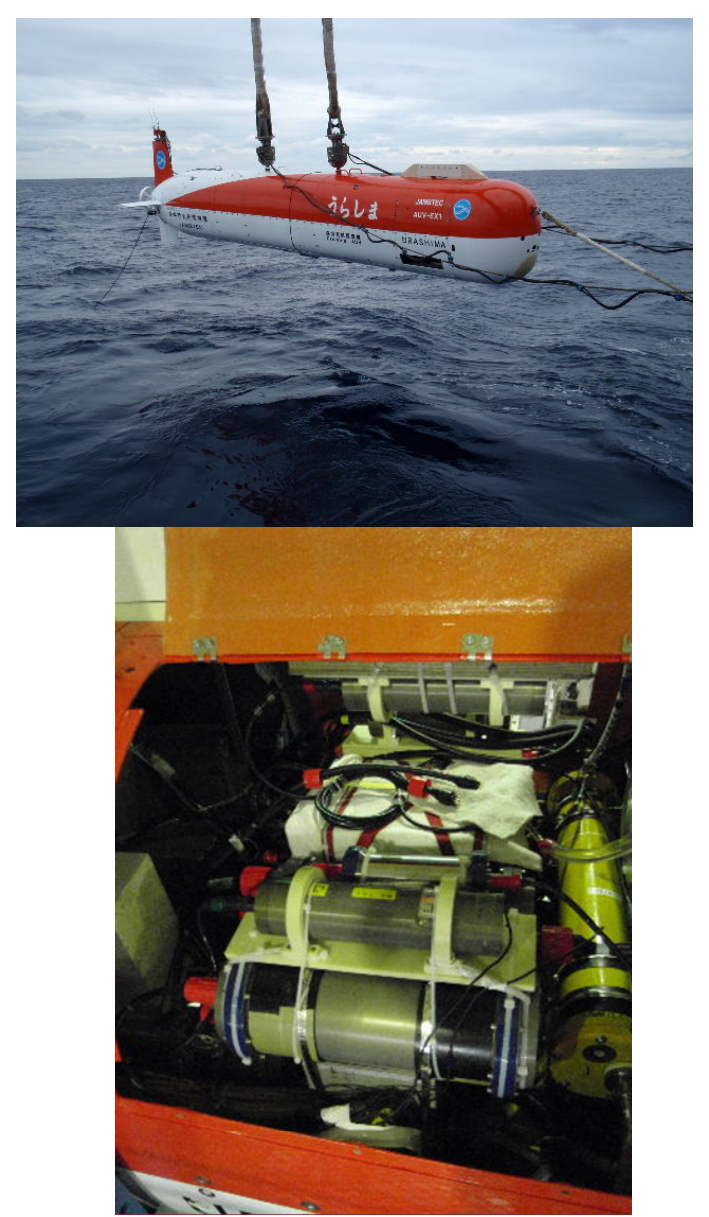

Fig.2 (Top) AUV Urashima before diving at YK11-11 cruise. (Bottom) Transmitter installed in the pay load of Urashima.

The research cruise, YK11-11, was conducted from Dec. 9-19, for examination of our new CSEM survey system. The research vessel "Yokosuka" and AUV "Urashima", both owned by JAMSTEC, were used for the survey. The target area was the Bayonnaise caldera, located in the Izu-Bonin region, the far-off southern area of Japan. As reported in 
Tanahashi et al. (2006), JOGMEC had conducted surveys targeting for SMS and found a huge hydrothermal sulfide deposit, named as the "Hakurei ore deposit" in the Bayonnaise knoll caldera. It was the first discovery of Kuroko-type ore deposit in the Izu-Bonin back-arc rift. The water depth is about $700-800 \mathrm{~m}$. There are many inactive sulfide chimneys at the central area, which mainly consist of sphalerite associated with chalcopyrite, galena, pyrite and barite. On the basis of comparison between the resistivity distribution obtained in this cruise and the seafloor geological settings around the Hakurei ore deposits, we can discuss how effectively new marine EM sounding techniques with AUV gives us information about SMS.

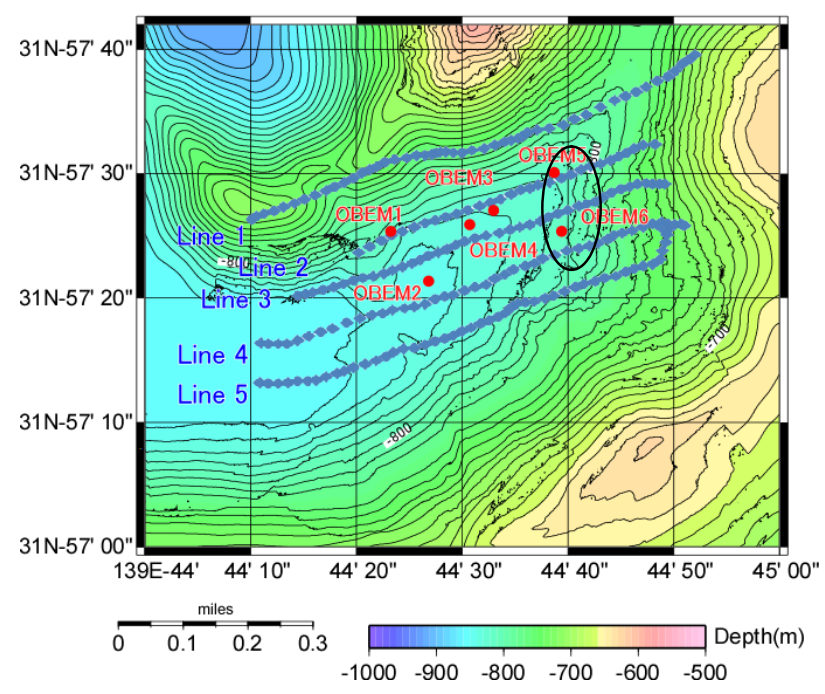

Fig. 3 Map for survey area. OBEM landing locations (circles) and survey line (diamonds) for AUV Urashima. SMS area=around OBEMs 5 and 6 (an ellipse)

\section{Result and discussions}

Due to the rough weather condition, we achieved only one dive of AUV in this cruise. Although such a limited survey time, we carried out five survey profiles around the OBEMs. Fig. 3 indicates the site map with bathymetry. Each profile has a length of about $1000 \mathrm{~m}$, and the profile spacing is about $150 \mathrm{~m}$. The AUV can swim with altitude of $10-70 \mathrm{~m}$ along the profiles. The cruising speed of AUV was about 2 knots. The source electrodes (copper wires) were towed behind the AUV, with dipole length of $10 \mathrm{~m}$. The direction and inclination of the source dipole were monitored by the magnetometer and tilt-meter attached to the dipole cable. During the cruise on profiles, AUV sent the artificial signal with every 30 second, so that the spacing of source points for CSEM was about $30 \mathrm{~m}$. The waveform of source signal was squared one, and the period was about 8 sec.

All of OBEMs/OBEs were successfully recovered, and recorded the signal from AUV. Fig. 4 indicates the received electric normalized by source amplitude at OBEMs 2 and 4 (Fig.3). In this case, the maximum amplitude of source current from AUV was about 70A (+/- 35A), and the maximum received amplitude was about $0.05 \mathrm{mV} / \mathrm{m}$ and $3 \mathrm{nT}$, respectively. Especially, the received electric field was clear even if the source-receiver separation was about $500 \mathrm{~m}$. This means that the source waves from all of transmitting points will be received by all of six seafloor receivers. In this case, the number of transmitter-receiver combination exceeds to 900 because the number of transmitting points was about 150 . It will give us information about the sub-seafloor resistivity structure around the SMS.

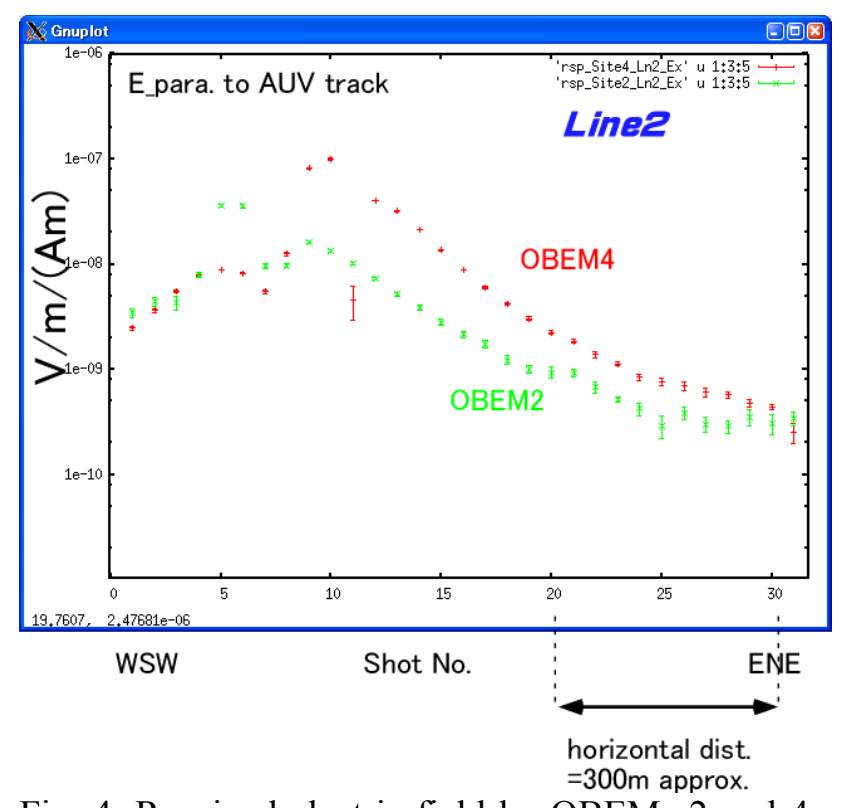

Fig. 4. Received electric field by OBEMs 2 and 4. Parallel component along the AUV track, Line 2. Normalized by source amplitude, length of source and receiver dipoles

We examined the forward calculation with assuming the realistic 3D seafloor topography and constant resistivity of seafloor (1 Ohm-m). It gives us the distribution of anomalous amplification or attenuation of electric field due to the underlying resistivity structures.

As a result, high conductive features are observed not only in the SMS exposed area, but 
also the surrounding area of SMS. Fig.5 indicates the anomalous ratio of received electric field by OBEMs 2 and 4 when the transmitter AUV dived along Line 2. At the caldera bottom, the anomalous attenuation was found, which would reflect highly porosity in the sedimentary layers. The anomalous electric field increase toward the end of Line 2 (from west to east), but it decrease around the SMS zone. I t would reflect both the mineral deposits in and around the SMS and high conductive pore water below the surface due to warm temperature by hydrothermal activities below the SMS.

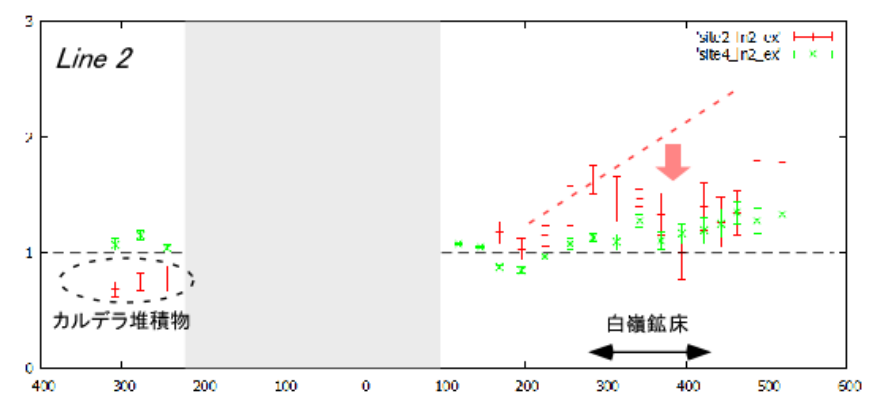

Fig. 5 Anomalous ratio of receive electric field by OBEMs 2 and 4 . $\mathrm{X}$ axis=horizontal distance between OBEM to AUV. Shaded area $=$ short source-receiver cases $(>150 \mathrm{~m})$, not discussed in this study.

\section{Conclusion}

We developed instruments for the marine CSEM survey with AUV, on which a transmitter was attached. The real field test, using R/V Yokosuka and AUV Urashima around the SMS at the Izu-Bonin island arc, south of Japan showed us the effectiveness of our survey system. We will conduct the amplitude analysis and inversion of obtained dataset to image the subseafloor structure around the SMS.

We conclude that our new technology imaging the near sub-seafloor structures will be useful for discussion about the geological background of SMS, and also be a powerful tool for the SMS detection and developments. In near futurem the three-dimensional CSEM inversion will give us a three-dimensional resistivity structure.

\section{ACKNOWLEDGEMENTS}

The authors thank the captain, crews and technicians of RV Yokosuka and operators of AUV Urashima. This project is supported by the Ministry of Education, Culture, Sports, Science \& Technology in Japan.

\section{REFERENCES}

Cairns, G., Evans, R. and Edwards, R. N., 1996, A time domain electromagnetic survey of the TAG hydrothermal mound.' Geophys. Res. Let., 23, 3455-3458.

Constable, S., and Srnka, L. J., 2007, An introduction to marine controlled-source electromagnetic methods for hydrocarbon exploration. Geophysics, 72, WA3-WA12.

Goto, T., N. Tada, J. Takekawa and H. Mikada, 2009, Feasibility study of marine CSEM survey for exploration of submarine massive sulphide deposits, AGU Fall meeting 2009, abstract \#GP43C-04.

Kowalczyk, P., 2008, Geophysical prelude to first exploitation of submarine massive sulphides, first break, 26.

Tanahashi, M., Shiokawa, S., Murayama, N., Takatori, R., 2006, A large hydrothermal sulfide deposit discovered in the Bayonnaise knoll, Izu-Bonin back-arc rift, Shigen Chishitsu, 56, 185-196 (in Japanese with English abstract).

Von Herzen, R. P., Kirklin, J., and Becker, K., 1996, Geoelectrical measurements at the TAG hydrothermal mound. Geophys. Res. Lett., 23, 3451-3454. doi: 10.1029/96GL02077. 